\section{Da rua para o bumbódromo: flagrantes do espetáculo em Parintins}

\author{
Patrícia Patrício
}

\section{Resumo}

Uma pesquisa sobre o Festival Folclórico de Parintins, realizada entre 2004 e 2007, somou características do ensaio aos métodos jornalísticos. O trabalho investigou como a festa se relaciona com a vida cotidiana, avaliando aspectos culturais, econômicos e políticos. Neste texto a atenção está focada nas transformações da festa, que nos anos 20 acontecia na rua, e passou a partir de 1988 para uma construção conhecida como "bumbódromo": um estádio com capacidade para 35 mil pessoas. A tradição do boi-bumbá, herdada do bumba-meu-boi nordestino, alterou-se com a passagem do tempo. Assim, a festa ganhou novas proporções e se transformou em um espetáculo midiático, com suas cenas exuberantes planejadas para seduzir não só a platéia local, como os telespectadores do festival.

Palauras-chave:

Parintins, Boi-bumbá, Cultura, Tradição, Mídia

\section{From the streets to the "bumbodrome" : aspects of the Parintins spetacular}

\section{Abstract}

A research about Parintins Folk Festival, conducted between 2004 and 2007, has added essay characteristics to the journalistic methods. The work investigates how the festival relates to the everyday life, evaluating cultural, economic and political aspects. In this text attention is focused in the festival transformations. In the 1920 's it happened in the streets. Since 1988 it has moved to a building known as "bumbódromo": a stadium for 35,000 people. The boi-bumbá tradition, inherited from Northeastern Brazil bumba-meu-boi, had changed as time passed by. Therefore, the festival has taken new proportions and it became a mediatic show, with flamboyant scenes planned to seduce not only the local public but the television audience as well.

Key words:

Parintins, Boi-bumbá, Culture, Tradition, Media 


\section{Apresentação da pesquisa}

Um trabalho sobre o festival de Parintins, cidade no Médio Amazonas cuja festa do boibumbá transborda de sentidos, jamais poderia se fundar nos vícios declaratórios de que padecem as redações. A narração da festa do boi-bumbá pode ampliar as fronteiras do jornalismo tradicional e adicionar, às características usuais da reportagem, reflexões mestiças, típicas do ensaio. No chamado "jornalismo declaratório”, em que o repórter se acomoda na entrevista por telefone ou email, falta a observação in loco, falta "a rua" com seus gostos, cheiros, sons, texturas. O profissional de imprensa torna-se incompleto ao se basear em apenas uma visão de mundo engessada e uma audição parcial para "pegar as aspas". Na academia, o pesquisador depende do trabalho de campo tanto quanto da biblioteca; na redação, o jornalista que não se alimenta da rua morre na secura das argumentações burocráticas, despidas da ação que movimenta a narrativa, ausentes de ação comunicativa entre os sujeitos.

Por isso, a tese Na ilha do boi de pano, a partir da qual este texto se desenvolve ${ }^{1}$, buscou estabelecer relações verdadeiramente humanas entre os sujeitos autor, "fonte" (no jargão de redações, os entrevistados) e leitor da reportagem. Assim, sob o signo da relação e da interação verbal (Bakhtin), a narrativa é permeável ao Outro e por ele permeada. Debaixo daquela floresta, nos meandros daquelas várzeas vive gente, e à gente carece se encontrar, perceber o mundo por um outro olhar, o olhar do Outro.

$\mathrm{O}$ relato empírico de $\mathrm{Na}$ ilha do boi de pano se desenrola em três atos: os dois primeiros narram as viagens de campo (2004 e 2005) e o terceiro traz uma narrativa visual da festa, acompanhada de textos em diálogo com as fotos, colhidas na segunda viagem de campo. Essa escolha pelo número três não é aleatória: em três encenações obrigatórias (ritual indígena, lenda e figura folclórica) durante três noites consecutivas, os bumbás Caprichoso e Garantido se enfrentam na arena do bumbódromo. Na construção em forma circular erguida em pleno centro de Parintins, com capacidade para 35 mil pessoas, desenrola-se a "ópera cabocla", nas palavras do pesquisador Simão Assayag, membro do Caprichoso.

"Boi de pano", expressão presente no título da tese, foi me dada por Enéas Gonçalves, prefeito em 2003. O torcedor do Garantido disse que a cidade vive de dois bois: o de carne, pois o município é o maior produtor bovino do Amazonas, e o de pano. Não significa muito, em termos brasileiros, ter o principal rebanho do Amazonas (107 mil cabeças de gado). Já o boi simbólico representa grande impacto cultural e midiático para além das fronteiras do Amazonas e do Brasil. Sem falar na importância econômica para o contexto local: num caso insólito de sazonalidade hiperconcentrada, em apenas três dias do ano o festival gera $40 \%$ do PIB do município (Braga, 2002), movimenta $\mathrm{R} \$ 40$ milhões e emprega 5 mil pessoas diretamente e 15 mil indiretamente. A cidade vê sua população dobrar: são 105 mil habitantes que recebem cerca de 100 mil turistas.

Localizada na Ilha Tupinambarana, no médio Amazonas, a sede do município de Parintins recebe, no último final de semana junino, os turistas, visitantes queridos, para celebrar a contenda entre Caprichoso, da cor azul e touro negro de estrela na testa e Garantido - vermelho, boi branco com coração na cabeça. Fizeram sucesso nos anos 90 os refrões das toadas (canções em ritmo de boi-bumbá) Vermelhou, no curral...
${ }^{1}$ Aqui apresenta-se parte dos resultados empíricos obtidos na pesquisa e estudo do festival de

Parintins ( $A M)$, apresentado como tese de doutorado em 19 de junho de 2008, na Escola de Comunicações e Artes da Universidade de São Paulo. Organizada em duas vertentes - empírica e teórica - a tese propõe uma maior interação dos sujeitos no fazer jornalístico, de uma forma diferenciada em relação à mídia tradicional.

\section{Estudos em Jornalismo e Mídia}


e Bate forte o tambor, é tic, tic, tic, tic, tic, tac.... São respectivamente, de Garantido e Caprichoso. Até 2004, a festa acontecia no tríduo de São Pedro, de 28 a 30 de junho. Porém, motivos econômicos e turísticos levaram o Governador do Estado, Eduardo Braga, a passar o festival para o último fim de semana junino, tornando assim a data móvel, pela primeira vez desde 1965, quando o bumbá passou da rua para um tablado de madeira - e, em 1988, para o bumbódromo de alvenaria. À medida em que o festival foi se popularizando na mídia, o número de visitantes aumentava e, quando os dias 28 a 30 caíam em meio de semana, dezenas de milhares de amazonenses paravam suas ocupações, pediam licença aos chefes ou mesmo faltavam ao trabalho para brincar com o bumbá. Por outro lado, ficava difícil aos turistas de outras latitudes irem a Parintins. Com efeito, o primeiro ano de mudança, 2005, viu duplicar o tráfego aéreo: 108 vôos e 303 pousos de aeronaves. Segundo a Capitania dos Portos, ancoraram 370 embarcações com 18700 passageiros, sem contar o número de iates, barcos particulares e não cadastrados que chegam pela Lagoa da Francesa e outros pontos não oficiais de desembarque.

Esses números, somados a outros dados que veremos adiante, deixam clara a importância econômica do evento, para além da simbólica. Porém, ao contrário do que se pode imaginar, os parintinenses não são "objetos" coisificados nessa relação. Os brincantes e organizadores do festival (comissões de arte, diretoria) se apropriam do circuito mercadológico e midiático para construir sua narrativa dramática e musical.

\section{Opções metodológicas \\ e ferramentas de trabalho}

Apesar de o nome oficial do evento ser Festival Folclórico de Parintins, o trabalho o compreende para além da manifestação dita "folclórica", como um fenômeno que se espalha pelo contexto social, cultural e econômico da região, preenchendo os espaços da vida cotidiana e o imaginário de parintinenses e visitantes do Brasil e do mundo. Afinada com uma visão sistêmica, não partitiva, busca flagrar o mundo em seu constante fluxo de significados. Assim, a pesquisa rechaça dicotomias e oposições como culto versus popular, visto que essas "camadas" se entremeiam.

A partir de Garcia Canclini, o projeto vislumbrou a relação do festival com o cotidiano parintinense, num continuum entre os aspectos culturais, econômicos, políticos e sociais do fenômeno. Os três dias de festival configuram um clímax na vida da cidade, mas nove meses antes do espetáculo houve sua preparação. Logo depois da festa há a comemoração do título (e o desfile de protesto, feito pelo boi contrário), a "fuga do boi" e a festa da padroeira, Nossa Senhora do Carmo, com quermesse e andor feito por artista de um dos bois, entre 6 e 16 de julho. Os parintinenses consideram esta uma celebração "só deles", enquanto o bumbá é de Parintins para o mundo. Depois das "férias de verão", entre julho e agosto, o trabalho preparatório para o próximo festival recomeça.

Assim afirma Garcia Canclini em As culturas populares no capitalismo: "A festa continua o cotidiano. Não é lugar da subversão e da livre expressão igualitária porque (...) as diferenças sociais e econômicas nela se repetem" (Garcia Canclini, 1983: 55). Em obra posterior, Culturas Híbridas, o autor elabora a questão em outros termos: 
Claro que as relações não são igualitárias, mas é evidente que o poder e a construção do acontecimento são resultado de um tecido complexo e descentrado de tradições reformuladas e intercâmbios modernos, de atores múltiplos que se combinam (Garcia Canclini, 1990: 243).

No processo de elaboração da tese, correram em paralelo as leituras e os trabalhos de campo. Antes, durante e após as viagens foi realizado o levantamento bibliográfico referente ao fazer jornalístico, à cultura popular em geral e amazônica em especial. As entrevistas uniram recursos metodológicos de história oral e a proposta do Diálogo Possivel (Medina, 1986). Esta obra ensina que a entrevista deve compreender o Outro, estabelecer interações entre os sujeitos pesquisados e o sujeito pesquisador.

Somaram-se ao Diálogo Possível as técnicas de entrevista aprofundada em história oral e captação de histórias de vida, sistematizadas por Paul Thompson e, no Brasil, defendidas por professores como José Carlos Sebe Bom Meihy, da História, e Ecléa Bosi, da Psicologia Social, só para ficar em dois exemplos da Universidade de São Paulo. A fértil produção de Medina no campo do jornalismo e da comunicação social oferece subsídios para qualquer aprendiz de feiticeiro ensaiar o signo do diálogo. Citarei apenas alguns títulos importantes, como Entrevista, o Diálogo Possível, Povo e Personagem, A Arte de Tecer o Presente, sem contar a série São Paulo de Perfil, da qual sou participante ativa desde 1993, e o Projeto Plural, que conta mais de uma década.

$A$ arte de tecer... em sua primeira versão, dos anos 70, foi escrita a quatro mãos com o jornalista Paulo Roberto Leandro. Na obra, Medina e Leandro oxigenam o chamado "jornalismo interpretativo" a partir do estudo de três interpretadores e pensadores da sociedade: Marx, Nietzsche e Freud. E a proposição pragmática resultante para os jornalistas é alicerçar a reportagem em quatro pilares:

1. oferecer uma panorâmica do contexto social e econômico do evento narrado;

2. apresentar suas raízes históricas;

3. ouvir e deixar falar as vozes do cotidiano - os personagens, os perfis humanos;

4. consultar as fontes especializadas no assunto em questão.

Esses quatro pilares construíram o edifício da reportagem $\mathrm{Na}$ ilha do boi de pano. Falemos da prática no campo: todas as entrevistas foram feitas depois da apreciação do festival e investigaram principalmente a relação do entrevistado com o boi-bumbá, o processo de criação artística e as memórias do boi. No caso específico de Fred Góes, compositor e membro da comissão de arte do Garantido, segui um roteiro temático indicado pela professora Ecléa Bosi, pois apresentei um perfil do artista como trabalho final de seu curso de pós-graduação: as perguntas sondavam sobre o primeiro contato com a música, os mestres, as influências no trabalho, os artistas contemporâneos importantes na época de formação.

A observação-experiência ${ }^{2}$ do fenômeno escolhido, o boi-bumbá de Parintins, passa por uma imersão cultural que se dá antes, durante e após as viagens de campo, pois o sujeito pesquisador mergulhou na produção simbólica dos sujeitos pesquisados: literatura, oratura, música, dança, artes plásticas e festas. Sem falar no levantamento bibliográfico, já mencionado.

O caderno de campo contou com uma versão online, o blog patnamazonia.blogspot.com. Tratou-se de uma amostra do caderno de campo
${ }^{2}$ Diante da tradicional "observação participante" utilizada em antropologia, etnologia e ciências sociais como um todo, Cremilda

Medina propõe, para a ciência aplicada da Comunicação Social, a observação-experiência. Ela se dá com todos os sentidos alerta,

para que o sujeito pesquisador possa se impregnar do contato com os sujeitos protagonistas e com seu ambiente sócio-cultural-políticoeconômico-ecológico.

\section{Estudos em Jornalismo e Mídia}


material, de papel e tinta. Por ser interativo, com botão de comentários para os leitores se manifestarem, ele se tornou um canal de relação com os sujeitos fruidores do texto. O projeto inicial apontava o blog como possibilidade de ensaio ou esboço da reportagem, porém, por dificuldades logísticas e lingüísticas, essa idéia mostrou-se inexeqüível.

Com a primeira versão da reportagemsaio construída, tentei o caminho inverso: editar o texto em pequenos blocos (a pedido dos leitores-comentadores). Também essa tentativa não funcionou. Não quero com isso defender o adágio "linguagem de internet é diferente de linguagem de jornal, revista ou livro", já que se tratam apenas de meios distintos. A técnica pode variar ligeiramente em função da tecnologia, mas a base de uma grande reportagem serve para qualquer suporte midiático - basta o comunicador ter sensibilidade e razão suficientes para o ajuste necessário.

A metodologia desenvolvida por Boris Kossoy de aproximação da imagem fotográfica constituiu outra contribuição importante para a narrativa visual da tese. Kossoy desenvolve suas proposições especialmente nas obras Fotografia e História (1988), Realidades e Ficções na Trama Fotográfica (1999) e Os Tempos da Fotografia (2007). Em Realidades e Ficções... Kossoy revela a ambigüidade da fotografia como documento e representação a um só tempo.

Aqueles que enxergam a fotografia apenas como documento (prisma "objetivo", de referência muito próxima ao real), perdem a perspectiva do processo criativo e das interferências subjetivas - deliberadas ou não - do autor-fotógrafo. E, por outro lado, quem vê apenas a fotografia em sua face subjetivista de representação duma realidade que consta do prisma do criador (e talvez de mais ninguém), perde o importante papel que a produção fotográfica desempenha para a historiografia, para o jornalismo, para o Direito e a ciência em geral. Portanto, é em sua dualidade de representação/documento que a fotografia deve ser encarada - lembrando sempre que ela é uma construção por sobre a referência da primeira realidade, aquela que faz parte da fotografia somente no momento em que o botão dispara o obturador.

Kossoy nos convida a desvendar a realidade interior da fotografia, não aquela visível nos elementos gráficos e de composição, mas "seus significados ocultos, suas tramas, realidades e ficções" (1999: 23). Esta realidade interior liga-se à primeira realidade e à própria referência do passado - mesmo que seja uma foto do último fim de semana, ou feita há horas atrás para comprovar um fato qualquer. $\mathrm{O}$ passado da fotografia começa logo após o instante em que ela é tomada.

Quando miramos uma foto, uma segunda realidade mostra-se no assunto da foto, em seu enquadramento, enfim em sua aparência, realidade exterior. É preciso estar mais atento para captar indícios da realidade interior. $\mathrm{E}$ isto o bom jornalista deve fazer, para evitar aquelas "legendas de cegos" e mais ainda, construir um texto breve que dialogue com aquela imagem em $\mathrm{o}$ ato III, narrativa visual da tese $\mathrm{Na}$ ilha do boi de pano. Nesse capítulo, a escritura do texto partiu da imagem para acrescentar detalhes relativos, porém não visíveis nela. Sempre que possível, buscou-se resgatar a história do assunto (por exemplo, a origem dos lamparineiros). 


\section{Nos bastidores da mídia: política, economia e novas tradições}

Curiosamente, tanto Caprichoso quanto Garantido intitulam-se "o boi da tradição". Mas, como diz Fred Góes, "a tradição existe para ser mudada”. Os lamparineiros que acendiam a festa na rua sem eletricidade durante os anos 20, hoje vestem fantasias brilhantes e carregam lamparinas cenográficas nas apresentações do Garantido.

Graças às interações entre os atores que transformam o bumbá em espetáculo, a "tradição" se altera. Como afirma Hobsbawn, "inventam-se novas tradições quando ocorrem transformações suficientemente amplas e rápidas" (Hobsbawn, 1984: 12). Eis o caso de Parintins: muito distante do folguedo original está atualmente a festa no bumbódromo, captada por câmeras de vídeo e fotógrafos brasileiros e estrangeiros, transmitida ao vivo e em rede nacional pelos canais SBT (TV A Crítica, afiliada local) e Amazon Sat (em parceria com a TV Amazonas, afiliada da Globo).

A organização do evento, realizada pela Agência de Comunicação do Governo do Estado do Amazonas, controla o acesso à arena do bumbódromo - palco circular, onde ocorre a apresentação. Isto, para atrapalhar o mínimo possível o espetáculo, e não "poluir" as imagens exuberantemente coloridas de mulheres vestidas de índias e alegorias com bichos fantásticos na tela da televisão, na foto do jornal ou da revista. Cada fotógrafo ou cinegrafista cadastrado tem direito a permanecer na arena durante apenas meia hora por agremiação. Todos se acotovelam na estreita passagem criada pelos brincantes, por onde chegam os personagens que vêm se apresentar aos jurados.

De acordo com o regulamento do Festival, dentre os brincantes há "itens" obrigatórios na avaliação do júri: cunhã-poranga (a moça mais bonita da tribo, no caso, do bumbá; deve ser escolhida na comunidade parintinense para não causar polêmicas), sinhazinha (estas podem ser "estrangeiras"), amo do boi (os "repentistas" que cantam versos ao boi), rainha do folclore, porta-estandarte, tribos (alas que representam fantasiosamente etnias indígenas), apresentador, levantador de toada (o análogo do bumbódromo ao puxador de samba na Marquês de Sapucaí). Nos bastidores da festa, há compositores, comissões de arte, artistas dos galpões que trabalham dedicados às alegorias gigantes, às fantasias, ou ainda aos capacetes dos tuxauas, guerreiros indígenas. Capacetes são adereços enormes, que chegam a medir $5 \mathrm{~m}$ de diâmetro, envolvendo não apenas a cabeça, mas todo o corpo: um cocar gigante de pluma, cor e brilho.

As agremiações gerenciam os recursos advindos dos governos estadual e federal, e das empresas Coca-Cola, Bradesco, Kaiser, Amazônia Celular, Correios, Petrobras e Nestlé. Somam em torno de 3,5 milhões de reais por bumbá. Em 2004, a Coca-Cola, patrocinadora oficial do evento, destinou 1,1 milhão de reais por bumbá e o Governo do Estado do Amazonas, 500 mil reais por agremiação. Deste modo,

o cargo do presidente de boi em Parintins (...) é tão importante quanto o de prefeito, de juiz de Direito, de bispo ou de presidente da Câmara de Vereadores (...). Além de administrarem, juntos, ao menos $\mathrm{R} \$ 7$ milhões por ano, os presidentes do Caprichoso e do Garantido têm presença constante na mídia nos três meses que antecedem, e durante, o Festival. Por tudo isso, são paparicados pelo baixo e alto clero da política estadual. ${ }^{3}$
3 Jornal A Crítica, Manaus, 24 de junho de 2005, p.5.

\section{Estudos em Jornalismo e Mídia}


Para efeito de comparação, o fundo de participação do município de Parintins foi de 9,5 milhões de reais em 2002 segundo dados do IBGE, e a receita municipal somou 39,5 milhões de reais no mesmo ano. Portanto, o orçamento de que dispõem os bumbás Caprichoso e Garantido equivale a quase $70 \%$ do fundo de participação do município. Dado o impacto econômico da festa, não se é de estranhar sua importância na vida política amazonense. Talvez por isso mesmo, para evitar rusgas políticas, os bumbás, oficialmente, não podem se dirigir às autoridades presentes no festival. Em 1997, Gil Gonçalves, apresentador do Caprichoso, recebeu uma penalidade de 10 pontos por saudar o governador.

Assim compara Odinéia Andrade, do departamento cultural do Caprichoso, em entrevista realizada em julho de 2004:

- O boi é como a política, aquilo contagia de tal forma... Boi, política e religião eu não me meto porque não quero confusão. Mas quando vejo estou no boi. Me chamaram para ser vereadora, só que não quero prometer pra não cumprir. Queira ou não queira, sou política. No boi já me envolvo, ajudo quem tá doente... boi e política é um vírus muito forte, semelhante, contagia. Digo que não quero e quando vejo tô lá. Sem que tu percebas as lágrimas estão caindo dos teus olhos. Já tá comprovado que boi não elege ninguém, você pode ter sido presidente [de boi] bom, se não passar confiança, não é eleito. O Enéas [Gonçalves, prefeito de $\mathrm{Pa}$ rintins] foi eleito pelas duas facções. Tem pessoas que dizem, ele é vermelho eu não voto. Isso é uma minoria. O Raimundo Reis Ferreira, Garantido ferrenho, ganhou muito bem.

O atual prefeito de Parintins, Frank Luis Garcia, mais conhecido como "Bi”, não poupou elogios ao profissionalismo na gestão do Garantido, apesar de ser torcedor do Caprichoso. $\mathrm{Na}$ coletiva de imprensa realizada em 22 de junho de 2005 na Cidade Garantido, área de 3 mil metros quadrados onde se concentram o prédio com salas para presidente e diretores da agremiação, e os galpões onde se produzem fantasias e alegorias, além da quadra de ensaios, assim falou o prefeito: "O boi está tranqüilo porque administra bem os recursos do governo e da prefeitura”. Às 13 h30 daquele mesmo dia, em evento disputado pela imprensa, o governador Eduardo Braga depositou 100 mil reais de emergência para cada um dos bois, sendo a verba destinada ao Caprichoso liberada diretamente nas contas dos artistas (que ameaçavam boicotar suas produções de alegorias e fantasias, pois não haviam recebido pagamento por seu trabalho). Não à toa, diretoria e comissão de arte "deram o pino", ou seja, faltaram à coletiva de imprensa do Caprichoso, marcada para o meio-dia. Já a coletiva do boi contrário movimentou o fim da tarde: mototáxis, bicicletas e motos coalharam a Cidade Garantido, trazendo jornalistas da imprensa local, da TV e jornal $A$ Crítica de Manaus, e alguns estrangeiros. (O tráfego na ilha Tupinambarana se dá basicamente em duas rodas, motorizadas ou não).

\section{O orçamento de que dispõem os bumbás Caprichoso e Garantido equivale a quase $70 \%$ do fundo de participação do município}

\section{Organização do território, profissionalização da festa}

Quem chega pelo Amazonas, após 18 horas rio abaixo - a melhor forma de perceber a relação entre tempo e espaço amazôni$\cos$ - percebe a aproximação de Parintins por uma bandeira vermelha, que identifica a Cidade Garantido, no oeste da cidade. O "curral" (quadra de ensaios e escritórios) do 
Caprichoso, com 2 mil metros quadrados, fica distante do rio e não se vê do barco. Um pouco abaixo da bandeira do Garantido aponta a torre da catedral de Nossa Senhora do Carmo. Esta, alinhada ao bumbódromo, forma o território neutro da cidade, que se divide em duas bandas: a leste o território azul do Caprichoso, a oeste o lado vermelho do Garantido. Até as placas de trânsito respeitam as cores dos bumbás. Dentro do bumbódromo circular, os logotipos das empresas patrocinadoras adequam-se à norma cromática dos bois, que nunca podem apresentar o tom do contrário. Assim, Coca-Cola e Bradesco vêm de azul no lado leste do Caprichoso.

Dentro da arena, a disposição das orquestras percussivas é diferenciada nos bumbás. Enquanto o Garantido posiciona sua batucada na área norte, em frente à tribuna de imprensa e aos jurados, o Caprichoso desloca a marujada mais para nordeste, ficando próxima à sua galera (torcida). No festival de 2005, o júri solicitou à marujada que mudasse, durante parte da apresentação, seu posto tradicional para poder melhor avaliar os percussionistas. Eles ganharam nota máxima e empataram com os concorrentes. Esse júri foi composto através de uma empresa escolhida por licitação pública (em 2005, a BDO Trevisan), porque em 2004 houve um atraso de duas horas devido à falta de jurados. Chamado às pressas para o júri, o ator Marcos Frota foi posteriormente desqualificado pela diretoria do Caprichoso, porque vestia uma camiseta do Garantido. A indicação de empresa por um processo público aponta, mais uma vez, o caminho da profissionalização do festival de Parintins. Processo este, defendido por Fred Góes, da comissão de arte do Garantido:
- Quando você vem falando em organizar muita gente critica. Em 99 qual era a grande máxima? Tudo tem que ser ensaiado, itens na academia, acompanhamento, coreógrafos... foi quando aconteceu o primeiro ensaio técnico no curral (...) fazemos a tomada de tempo para ver se tá dentro.

Assim como no carnaval do Rio, onde cada escola tem 90 minutos para se apresentar, o tempo de apresentação dos bumbás também é cronometrado: no máximo, duas horas para apresentar os "itens" individuais e coletivos e as cenas de lenda, figura típica regional e ritual indígena. Esses momentos carregam força cênica e aportam o tom amazônico à festa da morte e ressurreição do boi, celebrada do Nordeste a Santa Catarina. Sobre o palco da arena, a antropóloga Maria Laura Viveiros de Castro Cavalcanti, autora de vários estudos sobre o bumbá de Parintins, escreveu um artigo comparando os dois rituais, o linear do sambódromo e o circular do bumbódromo ${ }^{4}$.

O esmero na preparação do espetáculo parintinense é tão precioso que Hans Donner, mestre das vinhetas globais, ficou impressionado, segundo João Bosco "Baré" de Miranda, da comissão de arte do Garantido. As alegorias (cenários erguidos em estruturas de até 32 por 27 metros) têm movimento e são pensadas para criar impacto na platéia e no espectador. Durante três meses acontecem os ensaios cênicos; quatro ou cinco pessoas movimentam as estruturas das alegorias. Nove artistas principais cuidam da lenda, do ritual e da figura típica. Cada um comanda uma equipe de 25 a 30 pessoas: soldadores, escultores, pintores, pasteladores. Este usa papel de embrulho e goma de tapioca para moldar as alegorias.
${ }^{4}$ CAVALCANTI, Maria Laura Viveiros de Castro. "Os sentidos no espetáculo". Revista de Antropologia, vol.45 no.1, São Paulo, 2002

\section{Estudos em Jornalismo e Mídia}


${ }^{5}$ NEGRÃO, Keyla. "Parintins para o mundo ver: estratégias do discurso da televisão sobre amazonidade". XXIV Congresso Brasileiro de Ciências da Comunicação, Campo Grande, 2001.
Uma verdadeira divisão social do trabalho ocorre nos "QGs", os galpões dos bumbás. $\mathrm{E}$, quando o festival acaba, parte da mão-deobra parintinense é "exportada" para o eixo Rio-São Paulo, com a missão de elaborar carros alegóricos dos carnavais. Alguns deles participaram da criação do enredo da escola de samba Salgueiro em homenagem a Parintins em 1998. A experiência mereceu a seguinte análise em artigo de Keyla Negrão:

O saber prático do grupo, o domínio das narrativas orais da Amazônia garantiram a intervenção do grupo nas formas de construção dos discursos sobre amazonidade no horário nobre da televisão.

Assim sendo, o espetáculo também não é a forma mais sofisticada de dominação unilateral, mas é a linguagem contemporânea midiática que demonstra esse jogo $(. . .)^{5}$

Essa linguagem constrói e negocia uma identidade de Parintins para o mundo ver, como canta o refrão da toada replicado em títulos de trabalhos científicos, como o de Keyla Negrão, e parafraseado no livro de Júlio Cesar Farias, De Parintins para o mundo ouvir, que faz uma análise lingüística das letras das toadas. O espetáculo dramático dos bumbás de Parintins ganha novos relevos ao se converter, também, em espetáculo televisivo e tornar-se visível para milhões de espectadores. Como observa Keyla Negrão, a "visibilidade exige o domínio de certas regras e procedimentos (...) para produzir efeitos específicos". Pois os artistas de Parintins dominam plenamente essas regras, conforme vimos acima nos depoimentos de Fred Góes e Bosco Baré. Um outro episódio, flagrado no festival de 2004, mostra como até o improviso parece fazer parte do script do espetáculo: ao lado da alegoria do gigante Juma, com 12 metros de altura, uma cobra amarela e vermelha arde em chamas, e o apresentador do Garantido exclama: "Juma está furioso! Colocou fogo na floresta!" Os espectadores na galera (e talvez também os da telinha) chegam a pensar que o fogaréu era um efeito dramático. Logo vieram os bombeiros para apagar as chamas. No intervalo da apresentação, porém, ficou claro, era mesmo um acidente com a cobra, "feita de etafon, material inflamável que não resistiu à proximidade com a forte iluminação", de acordo com Bosco Baré.

O improviso em cima do imprevisto parece programado, e é programado o "improviso" do "repentista", o amo do boi. No auto do boi nordestino, amo do boi é o dono da fazenda. Mãe Catirina, grávida, pede ao peão Pai Francisco uma língua de boi para comer. Pai Francisco mata, sem saber, o boi mais querido da sinhazinha da fazenda, a filha do patrão. Todos entram em desespero até que resolvem chamar um pajé para ressuscitar o animal. A versão parintinense do auto do boi acrescentou uma profusão de elementos indígenas e, no folguedo, o amo do boi tem o papel de desfiar versos que exaltem seu bumbá. Eles parecem feitos de improviso, mas são cuidadosamente estudados e escritos nos notebooks dos amos do boi. Conforme assinala Gilda de Mello e Souza, "o cantador não é um artista iluminado que encontra as suas soluções de improvisos, é um profissional que se prepara longamente (...)" (Mello e Souza, 1979: 24).

Três centenas de ritmistas, outras tantas de artesãos e bailarinos liderados por uma dezena de artistas-músicos-coreógrafos garantem o encanto da "ópera cabocla" com força cênica, esplendor nas fantasias, beleza cabocla 
nas mulheres que dançam descalças, e o ritmo forte do tambor sob as melodiosas toadas. Ao longo de oitenta anos, a brincadeira de rua alumiada por lamparineiros transformou-se em espetáculo midiático exposto a potentes refletores.

\section{Considerações finais}

A maioria dos trabalhos na área de comunicação que estudam o festival de $\mathrm{Pa}$ rintins aborda as questões de identidade cultural, e alguns interpretam as transformações da festa de forma pessimista, encarando as mudanças como "degradação" do folguedo original. Aqui, temos claro que qualquer identidade é negociada num processo dinâmico, e o intuito deste texto foi flagrar as transformações de uma festa em seu contexto mais recente, de espetáculo que inova as tradições ao se midiatizar.

O boi-bumbá parintinense carrega sua origem nordestina (e, recuando mais nos séculos, ibérica). Resume o mito brasileiro da união das três raças: é branco na sinhazinha e na marujada, indígena no pajé e nos tuxauas, e negro em Pai Francisco, Mãe Catirina e na força da batucada. Revive a "tradição" octogenária e se renova, em diálogo com a atualidade. Seus artistas, criativamente, encenam um espetáculo que reverbera tanto ao vivo quanto diante das câmeras. Recortam mitos, lendas, histórias da Amazônia cheios de brilho, mas também narram as mazelas dos indígenas e denunciam o desflorestamento. Como numa ópera, há cenas cômicas, líricas, trágicas e dramáticas. Esta ópera cabocla, porém, não se faz em teatro italiano mas em um estádio em forma de arena para $35 \mathrm{mil}$ pessoas - com câmeras que a transmitem para milhões.

Parintins, aparentemente isolada na
Ilha Tupinambarana, rodeada pelo riooceano Amazonas, está perfeitamente integrada à era digital. Dispõe de provedor próprio, internet rápida, e aeroporto que encurta a distância temporal a Manaus para apenas uma hora de vôo, contra as 28 horas de barco rio acima, ou 28 , rio abaixo. Os parintinenses afirmam uma "identidade cabocla" conectada com o mundo; seu talento musical, cenográfico, artístico alimenta a economia local e garante um espetáculo que, através da mídia, ultrapassa fronteiras geográficas.

\section{Sobre a autora}

Patrícia Patrício, Doutora em Ciências da Comunicação pela USP, Conferencista convidada na ECA-USP (2003-2005), professora assistente na Unip (2007).

email: patriciapatricio73@yahoo.com.br

\section{Referências}

ASSAYAG, Simão. Boi-bumbá: festas, andanças, luz e pajelanças. Rio de Janeiro: Funarte, 1995. BAKHTIN, Mikhail. Questões de literatura e estética. 4.ed. São Paulo: Unesp, 1998.

Marxismo e filosofia da linguagem.6.ed. São Paulo: Hucitec, 1981.

BOSI, Ecléa. Memória e sociedade: lembranças de velhos. 2.ed. São Paulo: T.A. Queiroz/Edusp, 1987.

BRAGA, Sérgio Ivan Gil. Os bois-bumbás de Parintins. Rio de Janeiro: Funarte/Editora Universidade do Amazonas, 2002.

CAVALCANTI, Maria Laura Viveiros de Castro. Os sentidos no espetáculo. Revista de Antropologia, vol.45 no.1, São Paulo, 2002.

FARIAS, Júlio Cesar. De Parintins para o mundo ouvir: na cadência das toadas dos bois-bumbás CaprichosoeGarantido.RiodeJaneiro: Litteris, 2005.

\section{Estudos em Jornalismo e Mídia}


GARCIA CANCLINI, Néstor. Culturas híbridas. México: Grijalbo, 1990.

Culturas populares no capitalismo. São Paulo: Brasiliense, 1983.

HOBSBAWM, Eric. A invenção das tradições. Rio de Janeiro: Paz e Terra, 1984.

KOSSOY, Boris. Os tempos da fotografia. São Paulo: Ateliê Editorial, 2007.

. Realidades e ficções na trama fotográfica.

São Paulo: Ateliê Editorial, 1999.

LEANDRO, Paulo Roberto; MEDINA, Cremilda. $A$ arte de tecer o presente. São Paulo: ed. dos autores, 1973.

MEDINA, Cremilda. Entrevista, o diálogo possivel. São Paulo: Ática, 1986.

1996.

Povo e personagem. Canoas: ULBRA,

MELLO E SOUZA, Gilda. O tupi e o alaúde: uma interpretação de Macunaíma. São Paulo: Duas Cidades, 1979.

NEGRÃO, Keyla. Parintins para o mundo ver: estratégias do discurso da televisão sobre amazonidade. XXIV Congresso Brasileiro de Ciências da Comunicação, Campo Grande, 2001.

Recebido em 3 de março de 2008 Aprovado em 28 de abril de 2008 